\title{
Influence of martensite variant orientation on their mobility in a CuAINi alloy
}

\author{
G. Covarel, V. Pelosin and A. Rivière \\ Laboratoire de Mécanique et de Physique des Matériaux, UMR 6617 du CNRS, ENSMA, \\ BP. 40109, 86961 Futuroscope-Chasseneuil cedex, France
}

\begin{abstract}
The study has been performed on a Cu-13.6Al-3.1Ni (wt. \%) single crystal. Two specimens have been submitted to a treatment at $1133 \mathrm{~K}$ during $10 \mathrm{~min}$. followed by a water quench at room temperature. One sample was longitudinally strained, with a residual deformation of $4.5 \%$. Then, the internal friction has been measured in isothermal conditions over a large frequency range from $40 \mathrm{~Hz}$ to $10^{-4} \mathrm{~Hz}$ for measurement temperatures ranged between $294 \mathrm{~K}$ and $497 \mathrm{~K}$. The damping measured at high frequency $\left(>10^{-2} \mathrm{~Hz}\right)$ on the two samples is quite similar and is not changed significantly during the transitions (direct and reverse). On the contrary, at low frequency two effects are evidenced. First of all, on cooling, a sharp damping increase is observed from the beginning of the direct transformation on both samples. The damping is then, continuously decreased down to the martensite state. These evolutions have been ascribed to the fractal growth of the martensite. Second, during the first reverse transition, i.e. the first heating, the damping measured in the strained sample exhibits a maximum. This effect is diminished for the second reverse transition and is not present on the unstrained sample. The damping increase is discussed taking into account the incidence of the variant orientation on their mobility and the likely motion of structural defects introduced by the straining.
\end{abstract}

\section{INTRODUCTION}

The understanding of the physical and structural processes which occur during the direct and reverse martensitic transitions is necessary, especially when the - one or two way - shape memory effects have to be controlled. In this context, the study of the interface mobility (martensite / martensite, martensite / austenite) has been already undertaken particularly using internal friction measurements in anisothermal $[1,2,3]$ or isothermal $[4,5,6]$ conditions. For example, the study of a NiTi sample has shown that the martensite / martensite interface mobility is thermally activated at low frequency [4]. In addition, the activation energy corresponding to the martensite / martensite interface motion is lowered when the variants are oriented [5]. It is worth to remind that, in the studied $\mathrm{NiTi}$ alloy, no maximum damping was observed during the transition, underlining the low activity of the martensite / austenite interfaces.

On $\mathrm{CuAlNi}$ alloys, a study carried out on a single crystal [6] has established that no particular internal friction effect was observed during the heating from the martensite state up to the austenite while the damping was sharply increased during the direct transition. In fact, the damping behaves as if the martensite/martensite interface motion is frozen once the martensite is created. The explanation of this effect is not well understood but one of the most likely processes is the self-pinning of the interfaces because of the fractal growth of the martensite.

In order to define the influence of martensite variant orientation on their mobility, a new study has been undertaken in a strained $\mathrm{CuAlNi}$ single crystal.

\section{EXPERIMENTAL DETAILS}

The materials used for the present study was a Cu-13.6Al-3.1 Ni (wt.\%) single crystal, purchased at Orimi Steel (St Petersburg). Two samples (A and B) have been homogenised at $1133 \mathrm{~K}$ during 10 minutes, then water quenched at room temperature. In order to modify the orientation of the martensite variants, the $B$ specimen was longitudinally strained up to obtain a residual deformation of about $4.5 \%$. The occurrence of the transition and the transition temperatures were checked using DSC measurements.

For internal friction measurements, samples were cut in flat bar of typical dimension $64 \times 6 \times 1 \mathrm{~mm}^{3}$. The measurements were carried out in an evacuated $\left(2 \times 10^{-6}\right.$ torr $)$ inverted torsion pendulum [7]. The apparatus allows measurements by a frequency scan at a constant temperature over a large 
frequency range $\left(40 \mathrm{~Hz}\right.$ to $10^{-4} \mathrm{~Hz}$ ) with ten discrete frequencies per decade. The maximum strain was fixed at $5 \times 10^{-6}$. The internal friction $\left(Q^{-1}\right)$ and the real part of the shear modulus $(1 / \mathrm{J} 1)$ are determined at each frequency. $Q^{-1}$ is equal to $\tan \varphi$ where $\varphi$ is the phase lag between the applied sinusoidal stress and the resulting strain, $1 / \mathrm{J} 1$ is calculated through a parameter proportional to $\sigma / \varepsilon$.

As it is well known, internal friction measured in copper based shape memory alloys can exhibit a time dependent behaviour [8], thus, at each temperature, the data were recorded until obtaining reproducible values. In addition, to prevent from damping effects due to vacancy migration [9], samples $\mathrm{A}$ and $\mathrm{B}$ have been previously in situ annealed at $350 \mathrm{~K}$ for 24 hours.

The study has been performed on each sample increasing then decreasing the measurement temperature by isothermal stages.

\section{RESULTS}

Figure 1 shows internal friction spectra related to the strained sample for three measurement temperatures, $T_{m}$, corresponding to the martensite $\left(T_{m}=418 \mathrm{~K}\right)$ and the reverse transformation domain, martensite $\rightarrow$ austenite, $\left(T_{m}=458 \mathrm{~K}\right.$ and $\left.468 \mathrm{~K}\right)$. For frequencies higher than $10^{-2} \mathrm{~Hz}$, data levelled off and are almost superimposed, while for lower frequencies, the internal friction increases. This effect is much more important during the transformation.

Figure 2 compares the internal friction spectra corresponding to the strained (B) and in the nonstrained (A) samples during the transition at a measurement temperature close to $A_{F}-10 \mathrm{~K}$. The internal friction recorded in sample $\mathrm{A}$ is far smaller for frequencies below $10^{-2} \mathrm{~Hz}$.

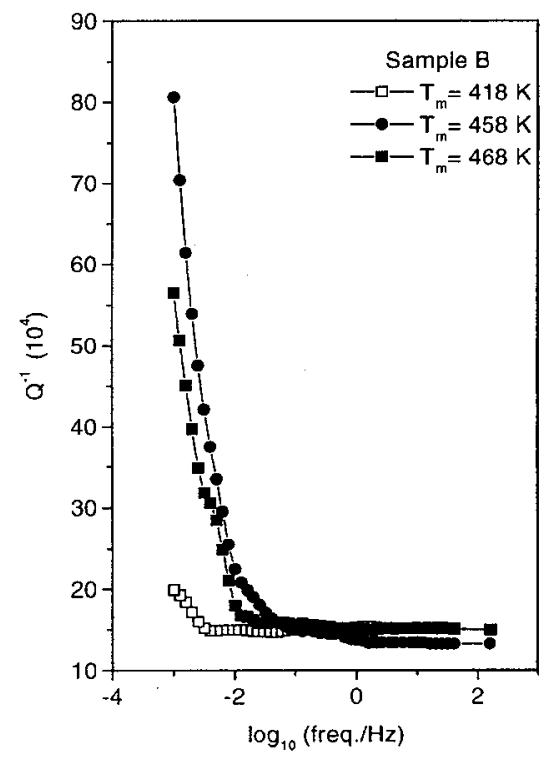

Figure 1 : Strained sample (B). Internal friction spectra versus frequency recorded during the first heating for three measurement temperatures.

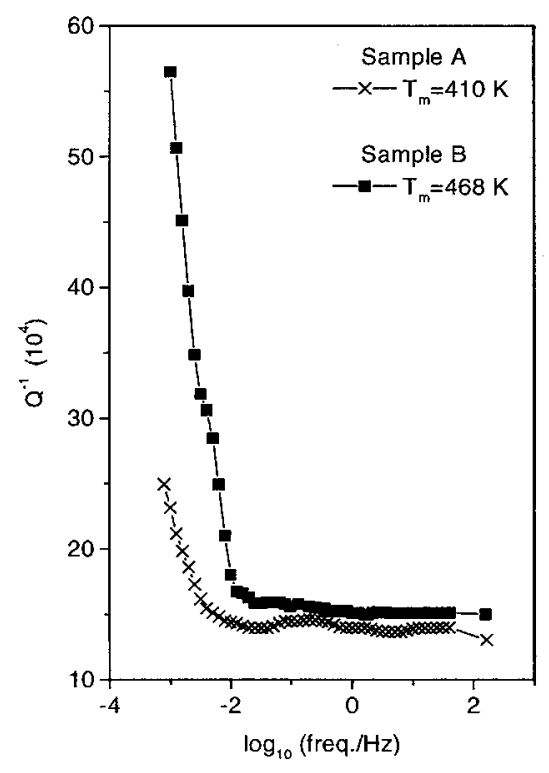

Figure 2 : Internal friction spectra obtained at $T_{m} \approx A_{F-}-10 \mathrm{~K}$, for sample $A$ (non strained) and sample $B$ (strained) during the first heating.

The $\mathrm{Q}^{-1}$ data, recorded by frequency scan at each measurement temperature, have been plotted as a function of the temperature for three frequencies $\left(10^{-3} \mathrm{~Hz}, 10^{-2} \mathrm{~Hz}\right.$ and $\left.1 \mathrm{~Hz}\right)$ in figure 3 , for the strained sample, and in figure 4 , for the non strained sample. Since the modulus does not particularly depend on the measurement frequency, only the values collected at $10^{-3} \mathrm{~Hz}$ have been reported. Non linear evolutions of the modulus in temperature are usually associated to structural modifications of the 
material. Figure 3 shows that the change of modulus evidenced between $418 \mathrm{~K}$ and $482 \mathrm{~K}$ proceeds in two stages including the transition : first a slight increase from $418 \mathrm{~K}$ to $443 \mathrm{~K}$, then, a sharp evolution from $448 \mathrm{~K}$ to $482 \mathrm{~K}$. On the contrary, as depicted by the figure 4 , the modulus of the non strained sample increases continuously from the martensite up to the austenite domain revealing unambiguously $A_{s}$ and $A_{F}$. Moreover, in the strained sample, the temperatures of the transformation domain are increased.

As regards the internal friction measured in the strained sample, figure 3 shows that, during the first reverse transition, it highly depends on the measurement frequency. Indeed, at $1 \mathrm{~Hz}$, it just slightly falls from the martensite up to the austenite domain. On the other hand, at $10^{-3} \mathrm{~Hz}$, the damping is sharply increased from $A_{S}$ up to $458 \mathrm{~K}$, then it decreases to level off in the austenite state. It can be noticed that the modulus associated to the damping maximum roughly corresponds to the average of the austenite and the martensite modulus. A similar damping effect, with a lower amplitude, is also observed at $10^{-2} \mathrm{~Hz}$.

The same experiments, carried out on the non strained sample (A), are shown in figure $4:$ the curves plotted at $1 \mathrm{~Hz}$ and $10^{-2} \mathrm{~Hz}$ are superimposed and the damping measured at $10^{-3} \mathrm{~Hz}$, both in the transition domain and in the austenite state is slightly higher.

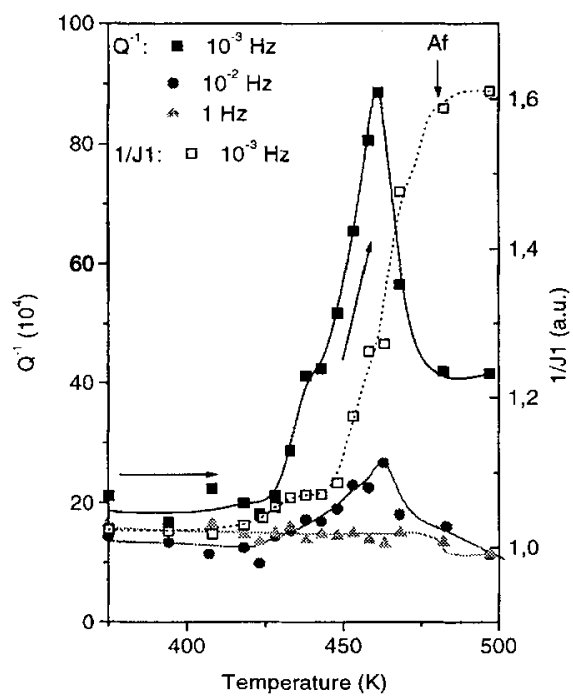

Figure 3: Sample B (strained) - Internal friction $\left(10^{-3} \mathrm{~Hz}, 10^{-2} \mathrm{~Hz}, 1 \mathrm{~Hz}\right.$, full symbols) and modulus $\left(10^{-3} \mathrm{~Hz}\right.$, open symbols) measured during first heating.

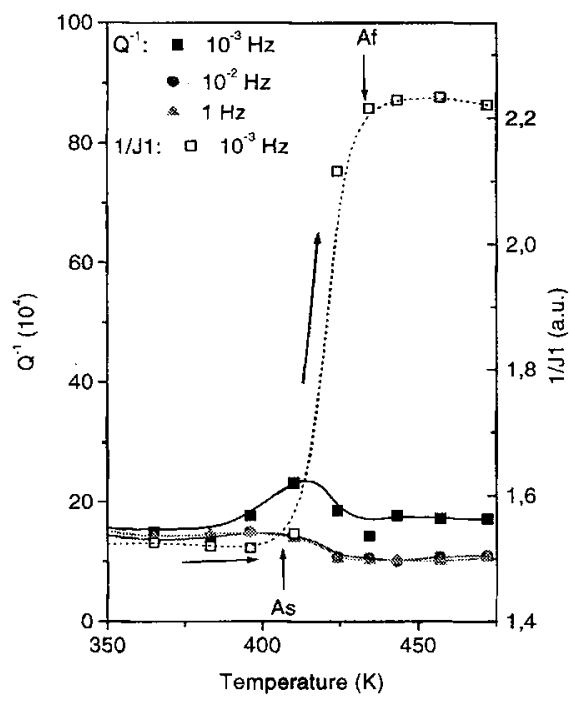

Figure 4: Sample A (non strained) Internal friction $\left(10^{-3} \mathrm{~Hz}, 10^{-2} \mathrm{~Hz}, 1 \mathrm{~Hz}\right.$, full symbols) and modulus $\left(10^{-3} \mathrm{~Hz}\right.$, open symbols) measured on first heating.

During the first reverse transformation, because of the shape memory effect, the strained sample dimensions have recovered their initial - as quenched - values. Then, after being cooled down to room temperature (in order to obtain a martensitic state), the sample has been submitted to a second reverse transition. In figure 5, the internal friction and the modulus measured at $10^{-3} \mathrm{~Hz}$ during the first and the second heating are compared : first, the temperature range of the modulus evolution is reduced and second, a maximum of the internal friction is still observed between $A_{S}$ and $A_{F}$. On the other hand, during the second heating the damping maximum value $\left(\mathrm{Q}^{-1}{ }_{\max }=63 \times 10^{-4}\right)$ is lower than during the first heating $\left(\mathrm{Q}^{-1}{ }_{\max }=88 \times 10^{-4}\right)$.

In spite of the restoration of the sample shape, the damping evolution stays different from that observed in the non strained specimen (A). In actual fact, some structural modifications could have been retained, even after the annealing in the austenite state ( 48 hours at $497 \mathrm{~K}$ ) due to the isothermal measurements. This assumption has justified the interest focused on the direct transition (austenite $\rightarrow$ martensite). Then, the measurements have been performed on cooling in the two specimen, A and B, after 
they have been subjected to a complete transition cycling : quenched martensite ( + deformation for specimen B) $\rightarrow$ austenite $\rightarrow$ thermal martensite $\rightarrow$ austenite. Figures $6 \mathrm{a}$ and $6 \mathrm{~b}$ display the damping evolution thus recorded in the two samples $\mathrm{A}$ and $\mathrm{B}$. Figure $6 \mathrm{a}$ confirms previous observations performed on similar specimens $[6,9]$. Indeed, at low frequencies, the damping is sharply increased from the very beginning of the direct transformation, then, it is steadily decreased during the martensite growth. Concerning measurements collected in sample $B$, it can be observed, in figure $6 \mathrm{~b}$, that the damping exhibits the same behaviour.

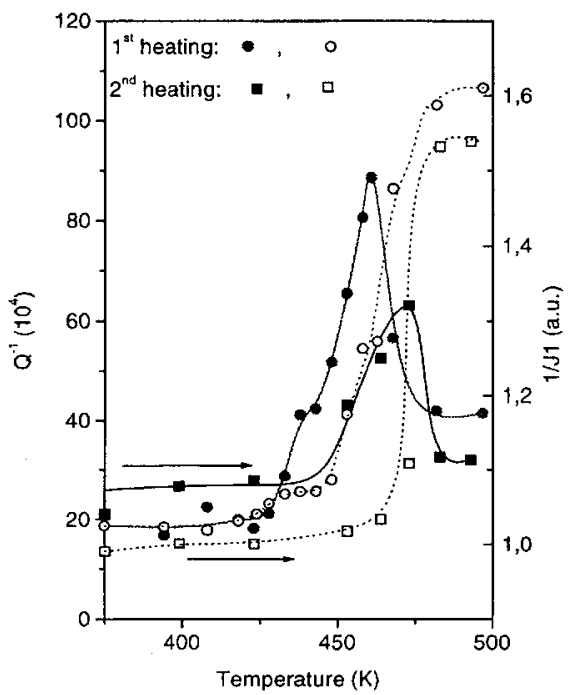

Figure 5 : Sample B- Internal friction (full symbols) and modulus (open symbols) plotted versus temperature and obtained at $10^{-3} \mathrm{~Hz}$ during the first and the second heating.
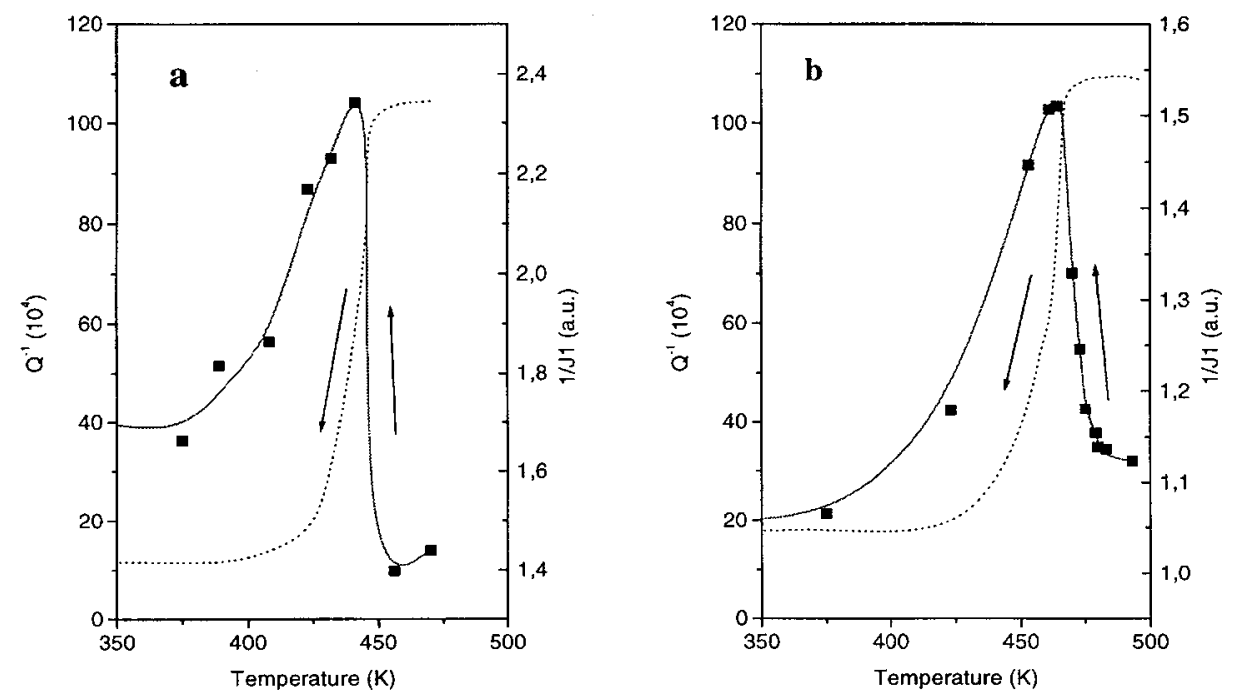

Figures 6a (left) and 6b (right) : Internal friction and modulus (dotted line) plotted versus temperature and recorded during the second cooling at $10^{-3} \mathrm{~Hz}$. Sample B (6a) and sample A (6b). 


\section{DISCUSSION}

One of the most striking results of this study shows that the damping evolution measured during the first reverse transition, which also means the first heating, is totally changed when the sample has been strained. A first assumption leads to associate the low frequency increase, observed in the deformed sample, to the martensite interface mobility which is facilitated when the variants are oriented. Such an argument is in good agreement with those already stated in the NiTi alloys [5]. Furthermore, during the second heating, the same damping effect is still observed but its amplitude is diminished indicating that some variants could have kept their oriented configuration [10]. This "orientation memory" is not surprising as $\mathrm{CuAINi}$ alloys are known for their ability to the two way shape memory effect [11].

Nevertheless, it seems quite doubtful that the interface mobility is the single process involved in the low frequency internal friction increase. Indeed, previous works have already stated that deformation in the martensite phase, also called marforming, is likely to bring about two structural modifications [12]. At low amount of strain, the martensite variant orientation occurs, then, when the strain is increased, lattice defects appear, mainly dislocations and stacking faults [13]. Those defects made the martensite phase more stable and then are responsible of the transformation temperature increase during the first reverse transition. In the present study, this feature has been observed, underlining the presence of defects.

As previously observed (figure 3), the evolution of both the modulus and the damping of the strained sample proceeds in two stages. In fact, the defect elimination and the phase transition are not necessary concomitant. While the sharp increase of the modulus occurring in the temperature range $448 \mathrm{~K}$ - $482 \mathrm{~K}$, is certainly associated to the austenite growth, the first modulus increased which happens between $418 \mathrm{~K}$ and $443 \mathrm{~K}$, could correspond to some defect elimination.

The introduction of dislocations by straining and their partial elimination during heating could then also explain the mechanical energy dissipation occurring during the first reverse transition. The annealing temperature has reached $497 \mathrm{~K}$ which is not necessary enough to eliminate all the defects. Then, on second heating, the remaining defects can once again activate the low frequency damping.

Concerning the damping evolution measured during the direct transition, the sharp increase at the beginning of the martensite growth was ascribed to the high structural instability of the austenite / martensite interfaces. On the other hand, the damping decrease down to Ms originates from the fractal growth of the martensite and the auto-pinning of the interfaces. The same damping evolution of sample $\mathrm{A}$ and sample $B$ (figures $6 a$ and $6 b$ ) indicates that the martensite growth process is similar in both specimens.

\section{CONCLUSION}

A CuAlNi sample has been deformed in the martensite state. The above described study has attempted to observe the influence of the martensite variant orientation on their mobility through internal friction measurements. A damping maximum has been evidenced, at low frequency, during the reverse transition. This effect is diminished after one transition cycle, and does not exist in a unstrained sample. Two hypothesis can be proposed.

Firstly, the self accommodating morphology of the variants could freeze their mobility. Indeed, it is shown that the oriented configuration, with less self pinning, leads to a greater damping. Some martensitic nucleation sites are retained in spite of the occurrence of the first transition that means the oriented growth of further martensite even after thermal cycling.

Secondly, structural defects, mainly dislocations, are also supposed to be introduced by the longitudinal strain. Their motion could play a important role in the damping increase process. But, they are partially eliminated by the annealing due to the occurrence of the first transition explaining the damping diminishing on the second heating.

In actual fact, these two processes are certainly both incriminated in the low frequency damping effect but their respective contributions are not yet unambiguously determined. 


\section{References}

[1] M. Morin and G.Guenin, Material Science Forum, 56-58, 499, (1990)

[2] J. Stoiber, J. E. Bidaux and R. Gotthardt, Acta Metall. Mater., 42, 12, 4059, (1994)

[3] J. Van Humbeeck, J. de Phys. IV, C8-371, (1996)

[4] F. Deborde, V. Pelosin and A. Rivière, Scripta Met., 33, 12, (1995)

[5] F. Deborde, V. Pelosin and A. Rivière, J. Phys IV, C8-401, (1996)

[6] G. Covarel, V. Pelosin and A. Rivière, Proceedings of ICIFUAS-12, J. of Alloys and Comp., in press

[7] J. Woirgard, Y. Sarrasin and H. Chaumet, Rev. of Scient. Inst., 48, 1322, (1977)

[8] M. P. Baron and M. Morin, Proceedings of the International Conference on Solid-Solid phase transformations 99, JIMIC-3, 1028, (1999)

[9] V. Pelosin, G. Covarel and A. Rivière, J. Phys. IV, 10, Pr6-59, (2000)

[10] R. Rapacioli, V. Torra and E. Cesari, Scripta Met., 22, 261, (1988)

[11] E. Cingolani, M. Ahlers and M. Sade, Acta Metall. Mat., 43, 6, 2451, (1995)

[12] E. Hornbogen, V. Mertinger and J. Spielfeld, Scripta Mat., 40, 12, 1371, (1999)

[13] D. Treppmann and E. Hornbogen, J. Phys. IV, C5-211, (1997) 